\title{
Early Posthypoglycemic Insulin Resistance in Man Is Mainly an Effect of $\beta$-Adrenergic Stimulation
}

\author{
Stig Attvall, Britt-Marie Eriksson, ${ }^{\star}$ Jesper Fowelin, Henning von Schenck, ${ }^{\star}$ lbe Lager, and Ulf Smith \\ Department of Medicine II, Sahlgren's Hospital, Gothenburg, ${ }^{*}$ Research Department, AB Hässle, Mölndal and \\ ${ }^{\ddagger}$ Department of Clinical Chemistry, University Hospital, Linköping, Sweden
}

\begin{abstract}
The insulin effect following hypoglycemia was studied with the euglycemic clamp technique in seven healthy subjects. Following an initial euglycemic clamp hypoglycemia was induced and after glucose recovery a second clamp was performed. Glucose production $\left(\boldsymbol{R}_{\mathrm{a}}\right)$ and utilization $\left(\boldsymbol{R}_{\mathrm{d}}\right)$ were studied with $\left[3-{ }^{3} \mathrm{H}\right] \mathrm{glucose}$. Each subject was studied four times; during infusion of placebo, propranolol, somatostatin, and a control study where hypoglycemia was prevented.

Hypoglycemia induced an insulin resistance with a lower steady state glucose infusion rate following the hypoglycemia during placebo as compared to the control study $(2.5 \pm 0.5$ and $4.8 \pm 1.0 \mathrm{mg} / \mathrm{kg} \mathrm{min}$, respectively, $P<0.05)$. The insulin resistance was due to an attenuated insulin effect on both inhibition of $\boldsymbol{R}_{\mathrm{a}}$ (impaired by 37\%) and stimulation of $\boldsymbol{R}_{\mathrm{d}}$ (impaired by $61 \%$ ). The insulin-antagonistic effect was completely prevented by propranolol but only partly by somatostatin.

Thus, early posthypoglycemic insulin resistance $(2.5-3.5 \mathrm{~h}$ after hypoglycemia) is a sustained effect mainly due to $\beta$-adrenergic stimulation.
\end{abstract}

\section{Introduction}

The current emphasis in diabetes treatment is to achieve an optimal metabolic control. However, intensified treatment leads to an increased incidence of hypoglycemic episodes $(1,2)$. It is well recognized that hypoglycemia is frequently followed by a period of hyperglycemia; the so called Somogyi effect $(3,4)$. Hypoglycemia is normally overcome by the release of different counterregulatory hormones $(5-8)$ and these $(9,10)$, as well as a relative insulin deficiency (11), have been proposed to cause the posthypoglycemic hyperglycemia. However, the relative importance of the individual counterregulatory hormones (catecholamines, glucagon, cortisol, growth hormone) is currently unknown although some evidence for the importance of catecholamines has been presented (9). The time course for the onset of action is different for the various counterregulatory hormones. The effect of $\beta$-adrenergic agonists and glucagon appears to be rapidly induced whereas growth hormone has a lag phase of several hours before the insulin-antagonistic effect becomes evident $(12,13)$.

The duration of the effect of these hormones is unclear. Although the effect of growth hormone appears relatively long-

Address reprint requests to Dr. Lager.

Received for publication 22 October 1986 and in revised form 18 February 1987.

J. Clin. Invest.

(c) The American Society for Clinical Investigation, Inc.

0021-9738/87/08/0437/06 \$2.00

Volume 80, August 1987, 437-442 lasting it is not known if also the emergency hormones, like the catecholamines, can induce a protracted insulin-resistant state. The current study was, therefore, carried out to evaluate the effect of insulin on glucose turnover following a hypoglycemic episode. To characterize the importance of the different counterregulatory hormones, studies were performed with the $\beta$-adrenergic antagonist, propranolol, and with somatostatin, which inhibits the release of glucagon and growth hormone during hypoglycemia.

\section{Methods}

Subjects. Seven healthy subjects, two females and five males, 24 to 28 yr of age were studied. All subjects were of normal weight, had normal fasting glucose levels, and lacked a family history of diabetes. None of the subjects took any regular medication. The characteristics of the subjects are shown in Table I. Informed consent was obtained from all subjects and the study was approved by the Ethical Committee of the University of Gothenburg.

Infusions. All infusions were made through a catheter placed in a cubital vein. Arterialized blood samples were drawn from the contralateral arm. Both arms were warmed with electric pads to increase the blood flow. Insulin (Actrapid, Novo, Denmark) was infused at a concentration of $0.1 \mathrm{U} / \mathrm{ml}$ in isotonic saline with $4 \mathrm{mg} / \mathrm{ml}$ albumin added to prevent glass adhesion. Glucose $(200 \mathrm{mg} / \mathrm{ml})$ was infused at variable rates in the same catheter as insulin. Potassium chloride $(0.1 \mathrm{mmol} / \mathrm{ml})$ was infused at a rate of $7 \mathrm{mmol} / \mathrm{h}$ to prevent hypokalemia. Propranolol $(5 \mathrm{mg}$ i.v. followed by $4.8 \mathrm{mg} / \mathrm{h})$ and somatostatin $(262 \mu \mathrm{g} / \mathrm{h})$ was given in the same catheter as insulin and glucose. Rates of glucose appearance $\left(R_{\mathbf{a}}\right)$ and disposal $\left(\boldsymbol{R}_{\mathrm{d}}\right)$ were determined by the infusion of $\mathrm{D}-\left[3-{ }^{3} \mathrm{H}\right]$ glucose (New England Nuclear, Boston, MA) dissolved in saline. A primed infusion of $25 \mu \mathrm{Ci}$ was given followed by a constant infusion of $15 \mu \mathrm{Ci} / \mathrm{h}$.

Study design. The study design is summarized in Fig. 1. Following constant infusion of $\mathrm{D}-\left[3{ }^{3} \mathrm{H}\right]$ glucose for $120 \mathrm{~min}$ to achieve isotopic equilibration, a euglycemic clamp (clamp I) was started with a primed insulin infusion for 10 min followed by a constant infusion of $0.5 \mathrm{mU} /$ $\mathrm{kg} \cdot \min$ during $120 \mathrm{~min}$. Arterialized venous blood was used to measure the blood glucose concentration every $5 \mathrm{~min}$ with a reflectometer (Reflomat, Clinicon International, Mannheim, FRG). The rate of glucose infusion was adjusted to maintain euglycemia at $4.5 \mathrm{mmol} / \mathrm{liter}$. The euglycemic clamp was performed for $120 \mathrm{~min}$ as reported previously (14). The glucose infusion was then stopped and the insulin rate increased to $2.5 \mathrm{mU} / \mathrm{kg} \cdot \mathrm{min}$ for $10 \mathrm{~min}$. The insulin infusion was stopped after $10 \mathrm{~min}$ and the glucose levels were continuously determined during the hypoglycemia and the phase of glucose counterregulation. $90 \mathrm{~min}$ after stopping the insulin infusion, glucose was given for $10 \mathrm{~min}$ to achieve euglycemia (4.5 mmol/liter). After $10 \mathrm{~min}$ stabilization a second euglycemic clamp (clamp II), identical to the first, was performed. Each subject was studied four times in a randomized order; with infusion of saline (placebo), propranolol or somatostatin, and in a control study where hypoglycemia was prevented by increasing the glucose infusion rate but maintaining the same insulin infusion. Infusion of saline, propranolol, or somatostatin was started at the beginning of clamp I and was continued throughout the study.

Analytical procedures. During the isotopic equilibration period blood samples for the determination of glucose (with glucose oxidase, Kabi 
Table I. Characteristics of the Subjects

\begin{tabular}{llllll}
\hline & Sex & Age & Height & Weight & $\begin{array}{l}\text { Relative body } \\
\text { weight* }\end{array}$ \\
\hline & & & & & $\%$ \\
M & 24 & 182 & 80 & 109 \\
& F & 26 & 170 & 67 & 105 \\
F & 27 & 172 & 67 & 102 \\
M & 27 & 176 & 75 & 111 \\
Mean \pm SD & 28 & 183 & 75 & 102 \\
& M & 28 & 194 & 93 & 113 \\
& & 28 & 173 & 60 & 91 \\
& & $27 \pm 1$ & $179 \pm 8$ & $74 \pm 11$ & $105 \pm 7$
\end{tabular}

* \% of ideal body weight according to the tables compiled by the Metropolitan Life Insurance Co. (Statist. Bull. Metropolitan Life Insur. Co., 1959, 40, Nov-Dec.)

Diagnostics, Stockholm, Sweden) and specific activity of labeled glucose were taken before (at zero time), after $80 \mathrm{~min}$ and henceforth every 20 $\mathrm{min}$. Blood samples for the determination of specific activity of glucose, levels of insulin, catecholamines, glucagon, cortisol and growth hormone were kept on ice, rapidly centrifuged, and the plasma stored at $-20^{\circ} \mathrm{C}$ until analyzed. Measurements of the specific activity of glucose were performed on deproteinized plasma. The samples were counted in a liquid scintillation counter (Packard Instrument Co., Downers Grove, IL) for $20 \mathrm{~min}$.

The insulin levels were determined by radioimmunoassay using Phadeseph Insulintest (Pharmacia Fine Chemicals, Uppsala, Sweden). Glucagon was assayed with antiserum E7 (15). This antiserum, which recognizes the carboxy-terminal region of glucagon, has been characterized with antiserum $30 \mathrm{~K}$ as reference (16). Catecholamines were determined by an isotope radioenzymatic method as modified by Eriksson et al. (17). Cortisol was determined with a fluorimetric method and growth hormone with a double antibody technique. The insulin and glucagon levels shown in Results during the euglycemic clamps are the mean values of three samples collected every 20 min during the second hour of each clamp. The adrenaline, cortisol, and growth hormone levels are the mean values of two samples collected every 30 min during the second hour of each clamp.

Calculations. The rates of glucose production $\left(R_{\mathrm{a}}\right)$ and utilization $\left(R_{\mathrm{d}}\right)$ were determined by the method of primed constant tracer infusion (18). This method assumes that rapid changes in the specific activity and concentrations of glucose do not occur uniformly within the entire glucose pool. To compensate for nonuniform mixing, the nonsteady state term of the equation was multiplied by a correction factor (pool fraction) of $0.65(19,20)$. During the glucose infusions the rate of glucose production

Time, min

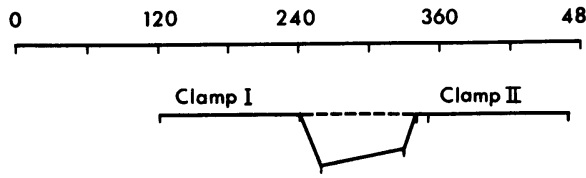

$\left[3-{ }^{3} \mathrm{H}\right]$ Glucose

Glucose $(200 \mathrm{mg} \cdot \mathrm{ml}-1)$

Insulin $\left(\mathrm{mU} \cdot \mathrm{kg}^{-1} \cdot \mathrm{min}^{-1}\right)$

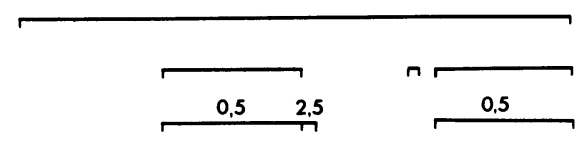

Control (----), Placebo, Propranolol, Somatostatin.

Figure 1. Study design. After $2 \mathrm{~h}$ of isotopic equilibration a euglycemic clamp (clamp I) was performed during $2 \mathrm{~h}$. Thereafter, hypoglycemia was induced and after $1 \frac{1 / 2}{h}$ counterregulation a new clamp (clamp II), identical to the first, was performed.
$\left(R_{a}\right)$ was calculated by subtracting the rate of infusion of exogenous glucose from the tracer-determined total rate of glucose production. The total glucose utilization $\left(R_{d}\right)$ for a given period of time could be estimated during the euglycemic clamps by adding the mean rate of the calculated endogenous glucose production during that period to the amount of glucose infused. As glucose infusion rate reached steady state during the second hour of each clamp, glucose production $\left(R_{\mathrm{a}}\right)$ and utilization $\left(\boldsymbol{R}_{\mathrm{d}}\right)$ during this period have been used in the calculations.

Data are shown as means \pm SEM. Significances of differences were analyzed with analysis of variance.

\section{Results}

\section{Hypoglycemic period}

Glucose levels. The glucose levels before induction of hypoglycemia, i.e., at the end of clamp I, were similar in all four studies (control 4.1 \pm 0.1 , placebo $4.5 \pm 0.1$, propranolol $4.2 \pm 0.1$, somatostatin $4.3 \pm 0.2 \mathrm{mmol} / \mathrm{liter})$. The glucose levels remained stable in the control group also during the higher insulin infusion rate (Fig. $2 a$ ). In the placebo study, glucose nadir (1.9 $\pm 0.2 \mathrm{mmol} /$ liter) was reached $10 \mathrm{~min}$ after stopping the insulin infusion. Glucose recovery was unaltered by propranolol (nadir $1.9 \pm 0.1$ $\mathrm{mmol} /$ liter) but impaired during infusion of somatostatin with both lower glucose nadir $(1.5 \pm 0.2 ; P<0.01$ versus placebo) and more prolonged hypoglycemia (Fig. $2 a$ ).

Hormone levels. The insulin levels when the insulin infusion was stopped were similar in all four groups (control 132 \pm 8 , placebo $121 \pm 7$, propranolol $122 \pm 6$, somatostatin $121 \pm 4 \mathrm{mU} /$ liter). This was also the case during the recovery period (Fig. $2 a$ ).

The epinephrine, glucagon, cortisol, and growth hormone levels remained stable in the control study where euglycemia was maintained even though the insulin infusion was increased following clamp I (Figs. $2 b$ and $c$ ). The epinephrine levels were higher during hypoglycemia in the propranolol as compared with the placebo group. The epinephrine levels were also slightly higher in the somatostatin group probably due to the more pronounced hypoglycemia in that study (Fig. $2 b$ ). The glucagon levels increased about threefold during the hypoglycemia in the placebo and propranolol groups, whereas the release of glucagon was completely prevented by somatostatin. The cortisol levels increased to a similar extent in all groups. The growth hormone increase was more pronounced in the propranolol as compared to the placebo group. No increase in growth hormone levels were seen when somatostatin was infused (Fig. $2 c$ ).

\section{Euglycemic clamps}

The mean glucose levels were similar during the clamps in all studies (control, clamp I: $4.2 \pm 0.1$, II: $4.2 \pm 0.1$; placebo I: $4.6 \pm 0.2$, II: $4.5 \pm 0.1$; propranolol I: $4.3 \pm 0.1$, II: $4.4 \pm 0.1$; somatostatin I: 4.5 \pm 0.1 , II: $4.8 \pm 0.2 \mathrm{mmol} / \mathrm{liter})$. The insulin effect, measured as steady state glucose infusion rate (SSGIR), ${ }^{1}$ was also the same during clamp I in all groups (control: $3.7 \pm 0.6$; placebo: $4.0 \pm 0.8$; propranolol: $3.9 \pm 0.6$; somatostatin: $4.4 \pm 0.8 \mathrm{mg} / \mathrm{kg} \cdot \mathrm{min}$ ).

The insulin effect following hypoglycemia (clamp II) was significantly impaired in the placebo as compared with the control group $(2.5 \pm 0.5$ and $4.8 \pm 1.0 \mathrm{mg} / \mathrm{kg} \cdot \mathrm{min}, P<0.05)$. This insulin resistance was completely prevented by the infusion of propranolol during the hypoglycemia $(4.1 \pm 0.6 \mathrm{mg} / \mathrm{kg} \cdot \mathrm{min})$ (Fig.

1. Abbreviations used in this paper: SSGIR, steady state glucose infusion rate. 

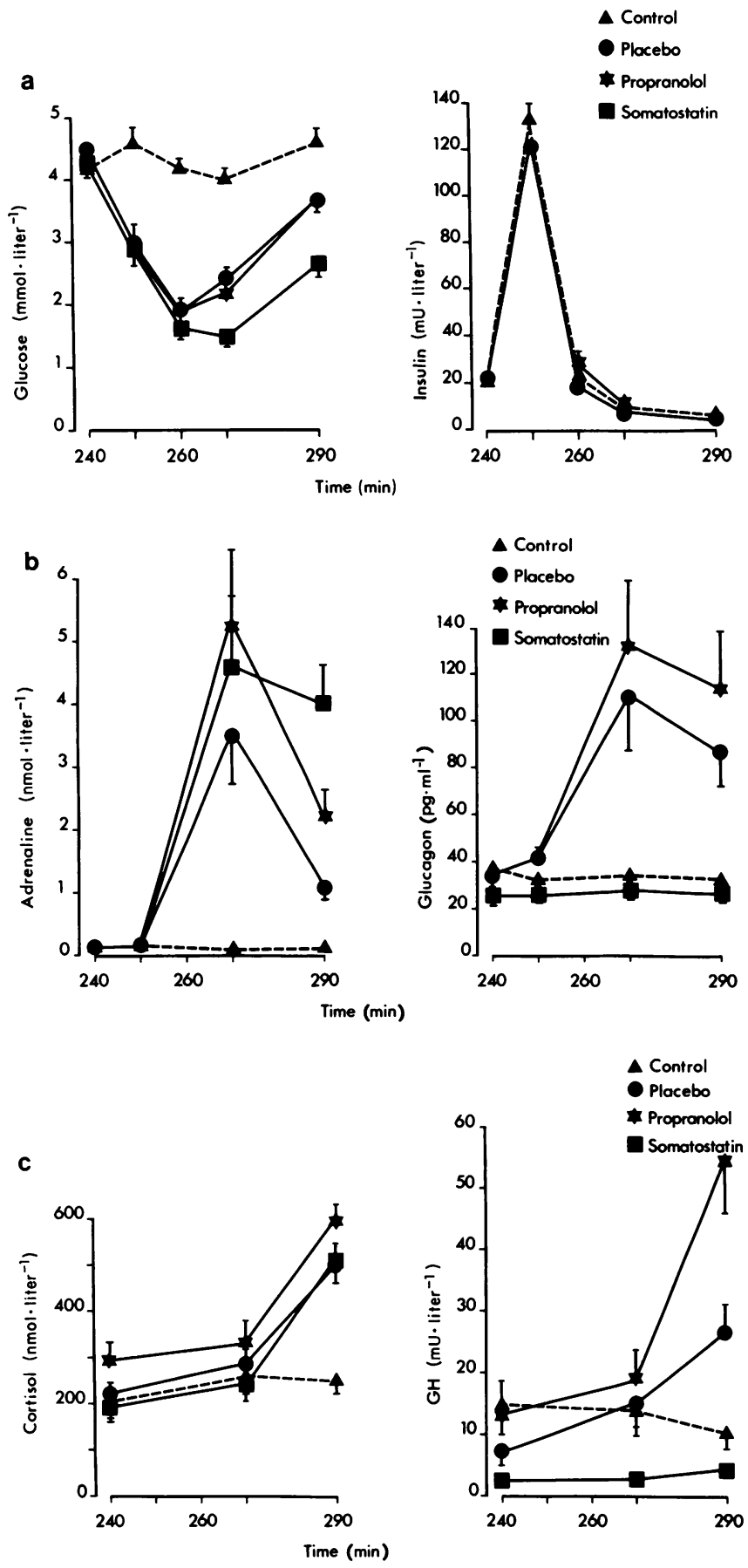

Figure 2. Blood glucose levels and plasma levels of insulin (a), adrenaline and glucagon levels $(b)$, cortisol and growth hormone levels $(c)$ during the hypoglycemia following clamp I.

$3 a$ ). The effect of the hypoglycemia to induce an insulin resistance was only partly prevented by the infusion of somatostatin, as the percent reduction of SSGIR between clamps I and II was significant in both the somatostatin $(23 \%)(P<0.05)$ and the placebo groups $(33 \%)(P<0.01)$ when compared to the control group. However, no difference was found between the control and the propranolol groups (Fig. $3 a$ ).

Glucose production $\left(R_{\mathrm{a}}\right)$ and utilization $\left(R_{\mathrm{d}}\right)$ were similar before clamp I in all groups (control 2.0 \pm 0.1 ; placebo $2.2 \pm 0.1$; propranolol $2.5 \pm 0.2$; somatostatin $2.2 \pm 0.1 \mathrm{mg} / \mathrm{kg} \cdot \mathrm{min}$ ). The
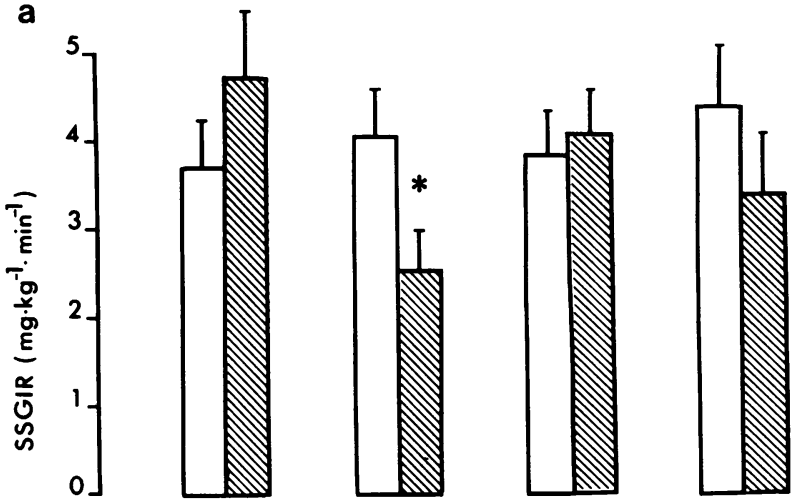

Control

Placebo

Propranolol

Somatostatin
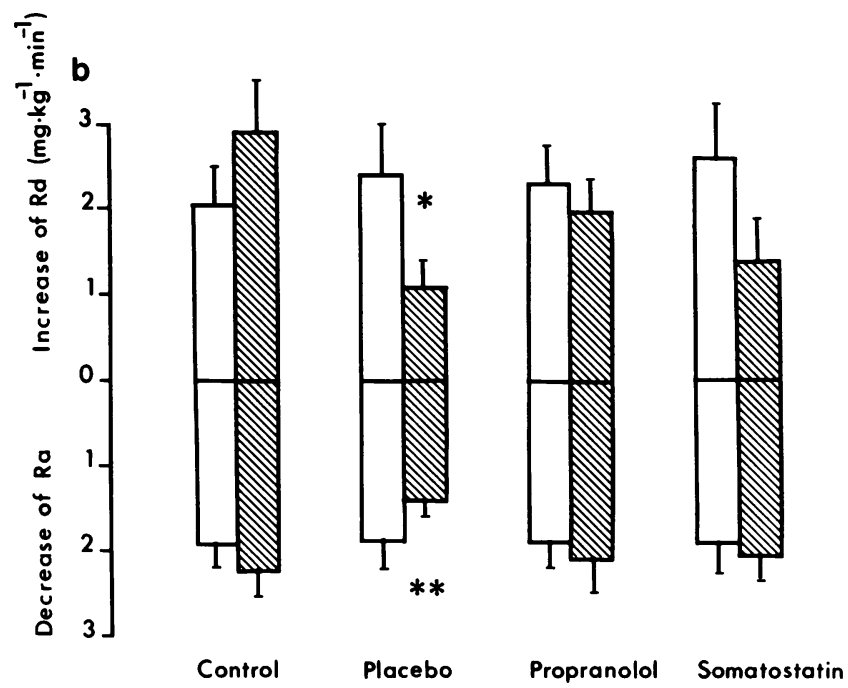

Figure 3. (a) SSGIR during clamp I (before) and clamp II (after) hypoglycemia. ${ }^{*} P<0.05$. (b) Increase of glucose utilization $\left(R_{\mathrm{d}}\right)$ and decrease of glucose production $\left(R_{\mathrm{a}}\right)$ during clamp I (before) and clamp II (after) hypoglycemia relative to basal (preclamp) levels. ${ }^{*} P<0.05$, ${ }^{* *} P<0.01$.

Clamp I ClampII

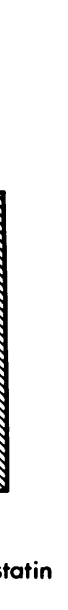

$$
{ }^{* *} P<0.01 \text {. }
$$

insulin resistance following the hypoglycemia was due to a less pronounced effect of insulin both to inhibit glucose production (decrease in $R_{\mathrm{a}}$ impaired by $37 \%$ ) and to stimulate glucose utilization (increase in $R_{\mathrm{d}}$ impaired by $61 \%$ ). This insulin resistance was completely prevented by propranolol. The insulin-antagonistic effect of the hypoglycemia on $R_{\mathrm{d}}$ was less pronounced during infusion of somatostatin but the glucose disposal rate was not significantly different from that of the control group (Fig. $3 b$ ).

Hormone levels. The insulin levels were similar during clamp I in all groups (Fig. $4 a$ ). The insulin levels during clamp II were slightly, but not significantly, lower in the placebo than in the control group (Fig. $4 a$ ). However, the less pronounced insulin effect following the hypoglycemia in the placebo group was not due to the slightly lower insulin levels since the degree of insulin resistance, calculated as the ratio between the insulin levels and the SSGIR, was significantly higher in the placebo as compared to the control group (Fig. $4 b$ ). 

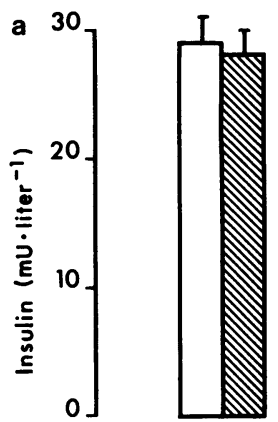

Control

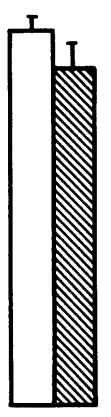

Placebo

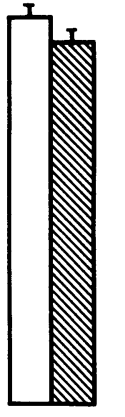

Propranolol

Somatostatin b
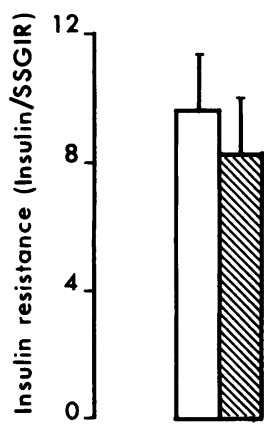

Control

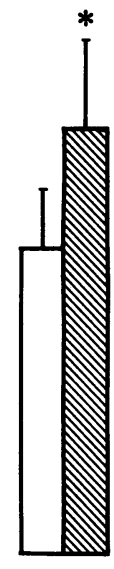

Placebo

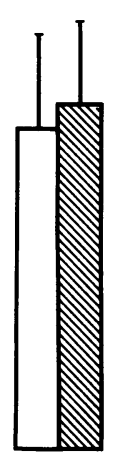

Propranolol Somatostatin
Figure 4. (a) Steady state levels of plasma insulin during clamp I $\square$ (before) and clamp II (after) hypoglycemia. (b) Insulin resistance expressed as plasma insulin/steady state glucose infusion rate (SSGIR) ratio, $\mathrm{mU} \cdot \mathrm{kg} \cdot \min (\mathrm{mg} \cdot 1)^{-1}$ during clamp I $\square$ (before) and clamp II $\square$ (following) hypoglycemia $* \dot{P}<0.05$.

The epinephrine levels were similar during clamp I in all groups (Table II). After the hypoglycemia the epinephrine levels had essentially returned to the initial concentrations during clamp II, except in the propranolol group where higher levels were seen. The norepinephrine levels were similar both before and during the two clamps in all groups (Table II).

The glucagon levels were similar during both clamps in the control, placebo, and propranolol groups (Table II). Infusion of somatostatin maintained the glucagon levels low throughout both clamps. The cortisol levels were similar in all groups (Table II). The growth hormone levels remained elevated following the hypoglycemia and this elevation was, similar to epinephrine, more pronounced in the propranolol group. Infusion of somatostatin completely prevented any rise in growth hormone during the hypoglycemia (Fig. $2 c$ and Table II).

Heart rate. The resting heart rate was similar in all groups (control: $51 \pm 3$; placebo $56 \pm 5$; propranolol $53 \pm 2$; somatostatin $54 \pm 3$ beats $/ \mathrm{min}$ ) and remained unchanged during clamps I and II. The heart rate increased during hypoglycemia but it was significantly $(P<0.001)$ lower during propranolol $(50 \pm 4$ beats/ $\mathrm{min})$ as compared to placebo infusion $(68 \pm 9$ beats/min). The heart rate remained unchanged in the control group.

\section{Discussion}

The present study clearly shows that hypoglycemia is followed by a marked insulin resistance maintained for at least 2.5-3.5 hours after the restoration of normoglycemia. Hypoglycemic episodes are usually of short duration as the patients ingest carbohydrates to increase the glucose levels. The early posthypoglycemic insulin resistance found in the present study is, therefore, likely to be clinically important and to contribute to the hyperglycemia frequently seen in patients with type I diabetes following hypoglycemia.

Glucose counterregulation was not impaired by the infusion of propranolol in these healthy subjects while somatostatin caused a significant impairment as also previously reported (7, 21). This is in marked contrast to type I diabetics who have a deficient glucagon release and where propranolol significantly impairs glucose counterregulation (22-24). The higher epinephrine, glucagon, and growth hormone levels seen in the present study during hypoglycemia and concomitant propranolol infusion are in agreement with other recent studies (25-27).

A reduced insulin effect on glucose metabolism can be due to an inability of insulin to inhibit splanchnic glucose production $\left(R_{\mathrm{a}}\right)$, to stimulate peripheral glucose utilization $\left(R_{\mathrm{d}}\right)$ or to a combination of both effects. In the present study hypoglycemia was followed by an attenuated insulin effect on both $R_{\mathrm{a}}$ and $R_{\mathrm{d}}$. However, the most pronounced impairment was seen on the ability of insulin to stimulate peripheral glucose utilization (reduced by $\sim 61 \%$ ). This is similar to our recent study of the effect of infused catecholamine on glucose metabolism (28). In this context, it is important to point out that the insulin levels used in the present study during the clamps are clinically relevant as corresponding levels are frequently seen in patients with type I diabetes during both conventional insulin therapy and continuous subcutaneous insulin infusion $(29,30)$.

Although propranolol did not alter glucose recovery following hypoglycemia, the $\beta$-blocker completely prevented the posthypoglycemic insulin resistance. The ability of propranolol to prevent the posthypoglycemic insulin resistance was due to a normalization of the insulin effect on both glucose production and utilization. These findings are in agreement with our recent study where epinephrine was found to be an important modulator of the insulin effect on both these parameters in the presence of physiological insulin levels (28). From a quantitative point of view, the most pronounced effect of epinephrine was to elicit an impairment of the insulin-stimulated glucose utilization $\left(R_{\mathrm{d}}\right)$. Infusion of propranolol completely overcame the effects of epinephrine (28). Taken together, these findings corroborate the importance of $\beta$-adrenergic stimulation for the posthypoglycemic insulin resistance.

The epinephrine, but not norepinephrine, levels were slightly elevated in all groups during clamp II. As this was not seen in the control study an effect of the increased insulin levels per se on epinephrine release or clearance can be excluded. The epinephrine levels were most markedly elevated in the group treated with propranolol. This is probably due to an impaired clearance rather than an increased release (25-27). Although it is well known that epinephrine is able to reduce glucose tolerance in healthy subjects (31), the elevations seen in the present study were probably much too small to make any significant contribution to the posthypoglycemic insulin resistance (32). A more likely possibility is that the insulin-antagonistic effect of prolonged elevations of catecholamines is sustained. In vitro studies have shown the ability of catecholamines to inhibit insulin binding to both rat $(33,34)$ and human fat cells $(35)$ and that this effect seems to become more pronounced with time (33). Insulin- 


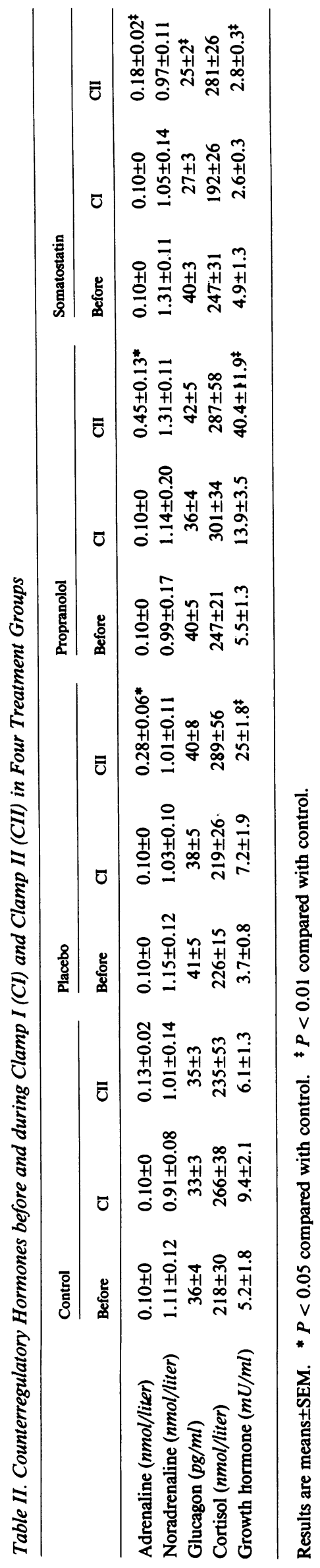

stimulated glucose transport is also markedly impaired in fat cells by $\beta$-adrenergic agonists (35-38).

Infusion of propranolol completely prevented the early posthypoglycemic insulin resistance while somatostatin only exerted a partial effect. Taken together these findings indicate that both $\beta$-adrenergic stimulation, glucagon and/or growth hormone can play a role. However, the catecholamine effect seems to be predominant. This is further supported by preliminary studies in IDDM, where the patients had impaired glucagon release (39). Also in these patients hypoglycemia elicited a marked insulin resistance that was mainly attributable to $\beta$-adrenergic stimulation.

Growth hormone exerts an insulin-antagonistic effect on both glucose production and utilization (12). However, this effect is not immediate but develops gradually after a lag phase of several hours $(13,40)$. This delay can be an important reason for the lack of any demonstrable effect of this hormone on the posthypoglycemic insulin resistance in the present study. Since also the insulin-antagonistic effect of cortisol has a lag phase of several hours (41) further studies are required to elucidate the potential importance of growth hormone and cortisol in modulating insulin action at a later stage following hypoglycemia.

The endogenous insulin release is normally inhibited during an insulin-induced hypoglycemic episode. One possible explanation for the less pronounced inhibition of the hepatic glucose production following hypoglycemia in the placebo group could, thus, be a lower endogenous insulin secretion than in the control group. However, since the evaluation of the insulin effect during clamp II was performed more than $1 \mathrm{~h}$ after restoration of normoglycemia a sustained suppression of the insulin release seems very unlikely (42). This is also supported by the finding that the peripheral insulin levels were similar during clamp II in both the placebo and the control groups.

In conclusion, the present study demonstrates that hypoglycemia is followed by a prolonged insulin resistance. This is due to an impairment of both the ability of insulin to inhibit glucose production and to stimulate glucose utilization. Propranolol is capable of completely preventing this effect of hypoglycemia that shows that $\beta$-adrenergic stimulation is of major importance for the development of the insulin resistance, at least in the early phase.

\section{Acknowledgments}

The excellent technical assistance by Ulla Skredsvik, R.N., and secretarial aid by Helena Carlsten is gratefully acknowledged. Professor Göran Lindstedt kindly performed the cortisol and growth hormone determinations. We are grateful to Ferring AB, Malmö, Sweden for supplying us with somatostatin.

This study was supported by grants from the Swedish Medical Research Council (project B-3506), Nordisk Insulin Fond, the Swedish Diabetes Association and Tore Nilsons Fond.

\section{References}

1. White, N., D. A. Skor, P. E. Cryer, L. A. Levandoski, D. M. Bier, and J. V. Santiago. 1983. Identification of type I diabetic patients at increased risk for hypoglycemia during intensive therapy. $N$. Engl. $J$. Med. 308:485-491.

2. Barbosa, J., and S. Johnson. 1983. Severe hypoglycemia during maximized insulin treatment of diabetes in a randomized clinical trial. Diabetes Care. 6:62-63.

3. Somogyi, M. 1952. Insulin resistance produced by insulin-hypoglycemia. Fed. Proc. 11:289. 
4. Somogyi, M. 1959. Exacerbation of diabetes by excess insulin action. Am. J. Med. 169-191.

5. Lager, I., H. von Schenck, and U. Smith. 1984. Improved but not normalized glucose counter-regulation during glucagon infusion in Type I (insulin-dependent) diabetes. Diabetologia. 26:337-342.

6. Bolli, B., G. D. Dimitriadis, G. B. Pehling, B. A. Baker, M. W. Haymond, P. E. Cryer, and J. E. Gerich. 1984. Abnormal glucose counterregulation after subcutaneous insulin in insulin-dependent diabetes mellitus. N. Engl. J. Med. 310:1706-1711.

7. Gerich, J., J. Davis, M. Lorenzi, R. Rizza, N. Bohannon, J. Karam, S. Lewis, R. Kaplan, T. Schultz, and P. Cryer. 1979. Hormonal mechanisms of recovery from insulin-induced hypoglycemia in man. Am. J. Physiol. 236:E380-385.

8. Santiago, S. D. T., F. Tse, W. E. Clutter, and P. E. Cryer. 1984. Defective glucose counterregulation limits intensive therapy of diabetes mellitus. Am. J. Physiol. 247:E215-220.

9. Popp, D. A., S. D. Shah, and P. E. Cryer. 1982. Role of epinephrinemediated $\beta$-adrenergic mechanisms in hypoglycemic glucose counterregulation and post-hypoglycemic hyperglycemia in insulin-dependent diabetes mellitus. J. Clin. Invest. 69:315-326.

10. Bolli, G. B., I. S. Gottesman, P. J. Campbell, M. W. Haymond, P. E. Cryer, and J. E. Gerich. 1984. Glucose counterregulation and waning of insulin in the Somogyi phenomenon (posthypoglycemic hyperglycemia). N. Engl. J. Med. 311:1214-1219.

11. Gale, E. A. M., A. B. Kurtz, and R. B. Tattersall. 1980. In search of the Somogyi effect. Lancet. ii:279-282.

12. Rizza, R. A., L. J. Mandarino, and J. E. Gerich. 1982. Effects of growth hormone on insulin action in man. Diabetes. 31:662-669.

13. Barusch-Marrain, P. R., D. Smith, and R. A. DeFronzo. 1982. The effect of growth hormone on glucose metabolism and insulin secretion in man. J. Clin. Endocrinol. Metab. 55:973-982.

14. Lager, I., P. Lönnroth, H. von Schenck, and U. Smith. 1983. Reversal of insulin resistance in type I diabetes after treatment with continuous subcutaneous insulin infusion. Br. Med. J. 287:1661-1664.

15. von Schenck, H. 1977. Production and characterization of an antiserum against pancreatic glucagon. Clin. Chim. Acta. 80:455-463.

16. von Schenck, H., and U. Nilsson. 1981. Radioimmunoassay of extracted glucagon compared with three non-extraction assays. Clin. Chim. Acta. 109:183-191.

17. Eriksson, B.-M. 1981. Aluminum foil instead of glass plates for thin-layer chromatography in radioenzymatic assay. Clin. Chem. 27: 341-342.

18. De Bodo, R. C. R., N. Steele, N. Altszuler, A. Dunn, and J. S. Bishop. 1963. On the hormonal regulation of carbohydrate metabolism. Studies with $C^{14}$-glucose. Recent Prog. Horm. Res. 19:445-448.

19. Cowan, J. S., and G. Hetenyi. 1971. Glucoregulatory responses in normal and diabetic dogs recorded by a new tracer method. Metab. Clin. Exp. 20:360-372.

20. Radziuk, Y., K. M. Norwich, and M. Vranic. 1978. Experimental validation of measurements of glucose turn-over in non-steady state. Am. J. Physiol. 234:E84-93.

21. Rizza, R. A., P. E. Cryer, and J. E. Gerich. 1979. Role of glucagon, catecholamines, and growth hormone in human glucose counterregulation. J. Clin. Invest. 64:62-71.

22. Lager, I., G. Blohmé, and U. Smith. 1979. Effect of cardioselective and non-selective beta-blockade on the hypoglycaemic response in insulin-dependent diabetics. Lancet. i:458-462.

23. De Feo, P., G. Bolli, G. Perriello, S. De Cosmo, P. Compagnucci, G. Angeletti, F. Santeusanio, J. E. Gerich, M. Motolese, and P. Brunetti. 1983. The adrenergic contribution to glucose counterregulation in type I diabetes mellitus. Diabetes. 32:887-893.

24. Kleinbaum, J., and H. Shamoon. 1984. Effect of propranolol on delayed glucose recovery after insulin-induced hypoglycemia in normal and diabetic subjects. Diabetes Care. 7:155-162.
25. Lager, I., H. von Schenck, and U. Smith. 1985. Glucagon release and glucose counter-regulation during hypoglycaemia. Acta Endocrinol. 110:107-113.

26. Viberti, G. C., H. Keen, and S. R. Bloom. 1980. Beta-blockade and diabetes mellitus. Effect of oxprenolol and metprolol on the metabolic cardiovascular, and hormonal response to insulin-induced hypoglycemia in normal subjects. Metab. Clin. Exp. 29:866-872.

27. Popp, D. A., T. F. Tse, S. D. Shah, W. E. Clutter, and P. E. Cryer. 1984. Oral propranolol and metoprolol both impair glucose recovery from insulin-induced hypoglycemia, in insulin-dependent diabetes mellitus. Diabetes Care. 7:243-247.

28. Lager, I., S. Attvall, B. M. Eriksson, H. von Schenck, and U. Smith. 1986. Studies on the insulin-antagonistic effect of catecholamines in normal man. Diabetologia. 29:409-416.

29. Buysschaert, M., E. Marchand, J. M. Ketelslegers, and A. E. Lambert. 1983. Comparison of plasma glucose and plasma free insulin during CSII and intensified conventional insulin therapy. Diabetes Care. 6:1-5.

30. Bending, J. J., J. C. Pickup, A. C. G. Collins, and H. Keen. 1985. Rarity of marked "dawn phenomenon" in diabetic subjects treated by continuous subcutaneous insulin infusion. Diabetes Care. 8:28-33.

31. Hamburg, S., R. Hendler, and R. S. Sherwin. 1980. Influence of small increments of epinephrine on glucose tolerance in normal humans. Ann. Intern. Med. 93:566-568.

32. Clutter, W. E., D. M. Bier, S. D. Shah, and P. E. Cryer. 1980. Epinephrine plasma metabolic clearance rates and physiological thresholds for metabolic and hemodynamic actions in man. J. Clin. Invest. 66:94-101.

33. Lönnroth, P., and U. Smith. 1983. Beta-adrenergic dependent down-regulation of insulin binding in rat adipocytes. Biochem. Biophys. Res. Commun. 112:972-979.

34. Pessin, J. E., W. Gitomer, Y. Oka, C. L. Oppenheimer, and M. P. Czech. 1983. $\beta$-adrenergic regulation of insulin and epidermal growth factor receptors in rat adipocytes. J. Biol. Chem. 258:7386-7394.

35. Lönnroth, P., C. Wesslau, G. Stenström, L. E. Tisell, and U. Smith, 1985. Reduced insulin binding to human fat cells following betaadrenergic stimulation-experimental evidence and studies in patients with a phaeochromocytoma. Diabetologia. 28:901-906.

36. Green, A. 1983. Catecholamines inhibit insulin-stimulated glucose transport in adipocytes in the presence of adenosine deaminase. FEBS (Fed. Eur. Biochem. Soc.) Lett. 152:261-264.

37. Smith, U., M. Kuroda, and I. A. Simpson. 1984. Counter-regulation of insulin stimulated glucose transport by catecholamines in the isolated rat adipose cell. J. Biol. Chem. 259:8758-8763.

38. Kirsch, D. M., M. Baumgartner, T. Rinninger, W. Kemmler, and H. U. Häring. 1983. Catecholamine-induced insulin resistance of glucose transport in isolated rat adipocytes. Biochem. J. 216:737-745.

39. Lager, I., S. Attvall, H. von Schenk, and U. Smith. 1986. Insulin resistance following hypoglycaemia is prevented by $\beta$-adrenergic blockade. Diabetologia. 29:287 A. (Abstr.)

40. De Feo, P., G. B. Bolli, M. M. Ventura, G. Perriello, S. De Cosmo, C. Lolli, J. E. Gerich, and P. Brunetti. 1985. Studies on the individual counter-regulatory role of glucagon, catecholamines, growth hormone and cortisol on augumented glucose production and reduced glucose utilization during continuous physiologic hyperinsulinemia in man. Diab. Res. (Suppl.) 1:326A.

41. Rizza, R. A., L. J. Mandarino, and J. E. Gerich. 1982. Cortisolinduced insulin resistance in man: Impaired suppression of glucose production and stimulation of glucose utilization due to a postreceptor defect of insulin action. J. Clin. Endocrinol. Metabol. 54:131-138.

42. De Feo, P., G. Perriello, S. De Cosmo, M. M. Ventura, P. J. Campbell, P. Brunetti, J. E. Gerich, and G. B. Bolli. 1986. Comparison of glucose counterregulation during short-term and prolonged hypoglycemia in normal humans. Diabetes. 35:563-569. 